\title{
Design, Manufacturing and Rig Test of a Small Turbojet Engine Combustor with Airblast Atomizer
}

\author{
Ahmet Topal, Onder Turan, and Sitkı Uslu
}

\begin{abstract}
Design of a gas turbine combustor is still difficult and an uncertain part of aero engine design process because of complex simultaneous processes such as turbulent mixing, reaction, multiphase flow and heat transfer. Therefore, having a proven design and experimental methodologies is so important to achieve combustor design targets in aero engine gas turbine projects. The present work provides an overview of an aero gas turbine combustor with airblast atomizer design, production and rig test process.
\end{abstract}

Index Terms-Combustor, turbojet, propulsion, airblast atomizer, gas turbine.

\section{INTRODUCTION}

Combustor design process includes mainly four phases as conceptual design, preliminary design, detailed design and validation. A crucial task in the design process is to define a concept. Because "the best engineering effort cannot totally be right a poor concept selection" [1]. Conceptual and preliminary phases of design are important, since it is at that stage that the largest influence on the final product is realized. A more realistic preliminary design will be shortened the detail design process. Therefore flow path design parameters should get feedback from detail design phase for the future design studies.

Operating requirements which a Gas Turbine Combustor has to meet in order to provide high engine efficiency and reliable operation are performance, feasible configuration, minimum emission and durability. These items define the combustor design criteria. In this perspective, a combustor with air-blast type fuel injection is designed and produced for a $90 \mathrm{lb}$. thrust turbojet engine. Detailed CFD studies have been performed to create the final geometry. In these studies, main performance parameters such as combustion efficiency, pressure drop, emissions and exit temperature profile checked to control performance requirements.

Performance characterization of the full annular combustor has been planned to perform in an atmospheric test rig. Obtained test results are compared with numerical results and discussed in this paper. A well-established combustor design, production and test approach was formulated to guide the development effort and eliminate possible errors for reducing

Manuscript received July 8, 2014; revised September 23, 2014.

Ahmet Topal is with TUSAŞ Motor Sanayii A.Ş., Eskişehir, 26003, Turkey (e-mail: ahmet.topal@tei.com.tr).

Onder Turan is with Anadolu University, Faculty of Aeronautics and Astronautics, TR-26470, Eskisehir, Turkey (e-mail: onderturan@anadolu.edu.tr)

Sitk1 Uslu is with TOBB University of Economics and Technology, Department of Mechanical Engineering, Sogutozu Cad. No. 43, 06560 Ankara/Turkey (e-mail: suslu @ tobbetu.edu.tr). required development time.

\section{Combustor Design, Production And Rig Test}

First and second steps of the combustor design process are the concept definition and flow path design. In the conceptual design phase performance requirements and geometric constraints have been selected. Considering the current configuration, performance parameters and the design criteria, combustor conceptual design has been realized. Following to the conceptual design phase preliminary design studies have been initiated and basic dimensioning, flow split calculations and one-dimensional liner temperature calculation have been performed. These studies was an iterative process and so important to decrease time of the detail design. When the combustor geometry optimized in preliminary design, detail design studies have performed by using CFD tools. First three step of this design process is mapped in a more detailed manner in Fig. 1.

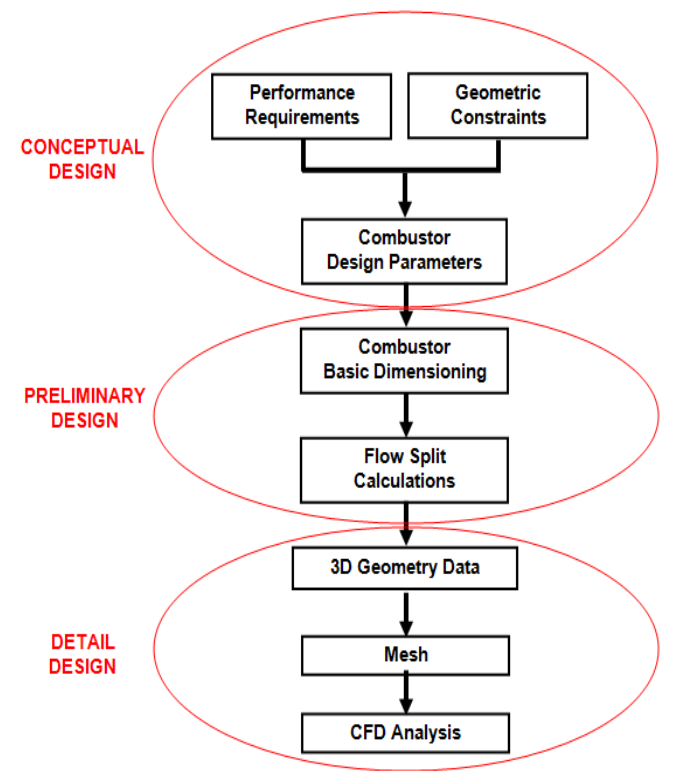

Fig. 1. Detail process map of conceptual, preliminary and detail design phases.

Combustor is a through flow annular type and has a dump type diffuser. Fuel preparation mechanism is airblast atomizer type fuel injection and consists of 7 co-flow type radial swirl airblast atomizers. Radial type airblast atomizer is co-flow type and has two air streams as primary and secondary (see Fig. 2). Co-flow type swirler has stability advantage in respect of the counter-flow type swirler however combustion efficiency is higher in counter-flow. Because of the stability is a more important issue for us, co-flow type has been preferred. 


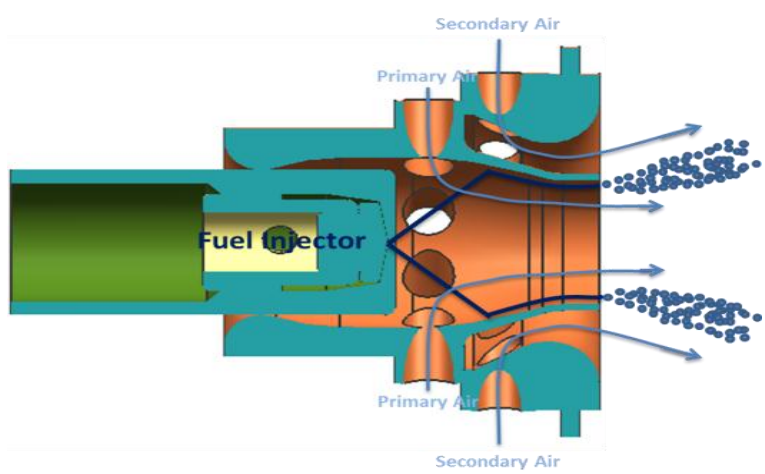

Fig. 2. Geometry of the air-blast atomizer.

For the conceptual design phase, it is so critical to determine performance parameters such as combustion efficiency, pressure drop, outlet temperature profiles etc. In respect of these parameters and geometrical constraints, combustor flow path created in one and two-dimension.

Loading, intensity and the residence time are the critical parameters of the preliminary design phase. Combustor volume was determined in accordance to these parameters. Following to determineation of the 2D path of the combustor, flow split analysis performed by using a preliminary combustor design tool. This design tool divided the flow path to small segments. Air and fuel mass flows have been calculated for each segment and by the way adiabatic flame temperature calculations have been conducted. Flame temperature calculation is critical for accurate liner metal temperature estimation. Flame temperature values are predicted based on the adiabatic flame temperature calculation and zone efficiencies. Look up tables have been used for specified pressure, temperature and equivalence ratio [2]. To calculate flame temperature in primary zone, efficiency correlation of Odgers was used [3]. For secondary zone efficiency, same correlation has been modified.

$$
\eta_{P Z}=0.72+0.29 \tanh \left[1.5475 \times 10^{-3}\left(T_{a}+108 \ln P_{a}-1863\right)\right]
$$

$\eta_{S Z}=0.80+0.29 \tanh \left[1.5475 \times 10^{-3}\left(T_{a}+108 \ln P_{a}-1863\right)\right]$

However these correlations are the maximum achievable values of primary and secondary zone and dictate fixed combustion efficiency. Therefore an efficiency trend line has been defined for segments. Flame temperature values obtained from CFD and preliminary calculations compared in Fig. 3.

1D liner metal temperature calculations performed based on Lefebvre's correlation [4]. Combustor liner thickness is so small and by the way, to simplify the solution, the temperature difference across the combustor liner has been ignored. In Fig. 4 , outer and inner liner wall temperature variation can be seen in $1 \mathrm{~mm}$ segments. Sudden decrease in the temperature is associated with the primary, secondary and dilution air. As it can be seen in the graph, most critical location for metal temperature is the end of the secondary zone.

After completing the preliminary design studies, detail design studies were initiated for tuning of the flow path and liner holes. Combustor performance parameters that are defined in conceptual design phase must be validated computationally. An effective primary zone recirculation is important for the stability and combustion efficiency. Critical swirl number value must not be lower than the 0.6 . Recirculation is important to transport heated gas to the airblast atomizer to evaporate the fuel droplets and also create a low velocity region for combustion. However it must be careful about higher value of swirl number because of the penetration of the recirculated flow inside to the airblast atomizer. This situation will cause unstable condition. Created recirculation zone can be seen in Fig. 5 and as a result of the recirculation zone maximum temperature is located in this region.

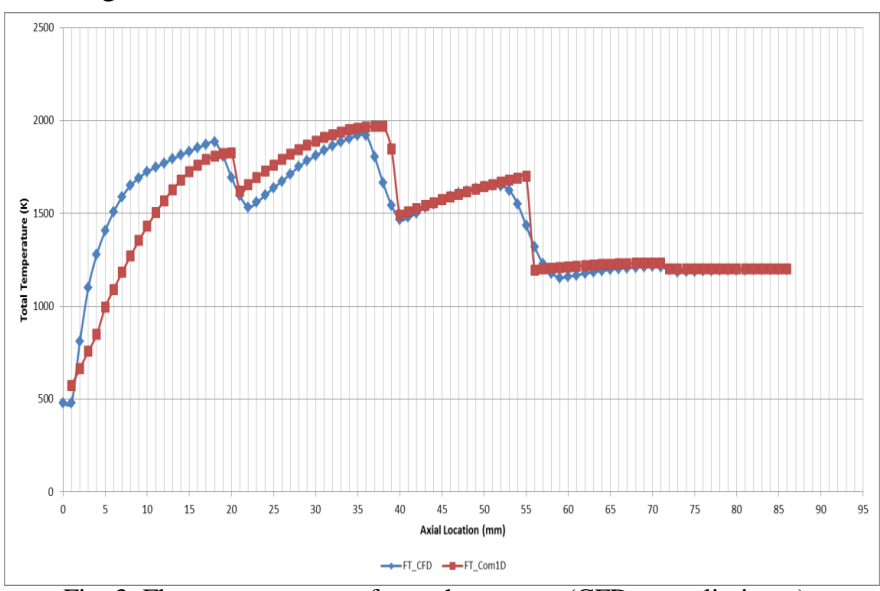

Fig. 3. Flame temperatures for each segment (CFD vs preliminary).

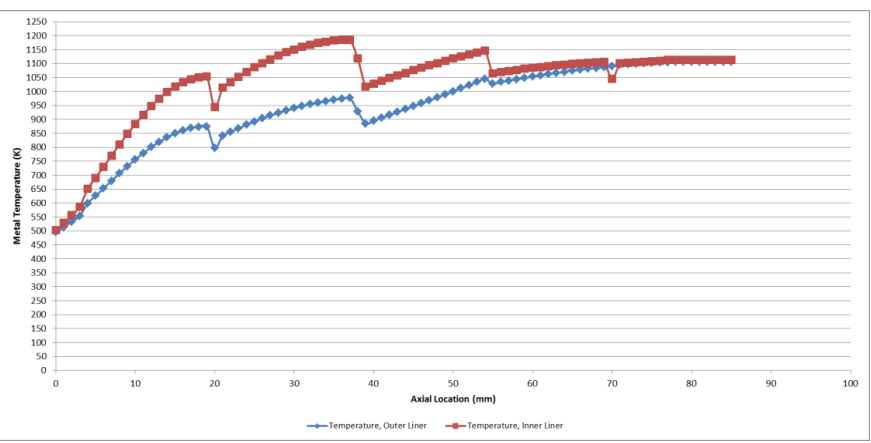

Fig. 4. 1D Liner metal temperature values.

Adiabatic flamelet model has been used for the combustion simulation. Fuel is injected from the exit of nozzle with a low velocity and small size droplet. Droplet temperature is chosen as same as the combustor inlet temperature. By this method, it is supposed to be gaseous to avoid complexities associated with atomization and evaporation [5] (see Fig. 6).

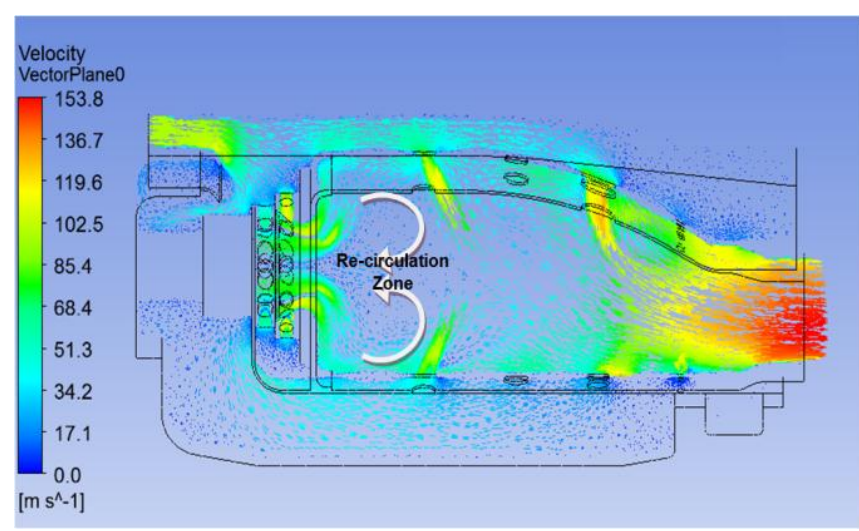

Fig. 5a. Recirculation zone. 


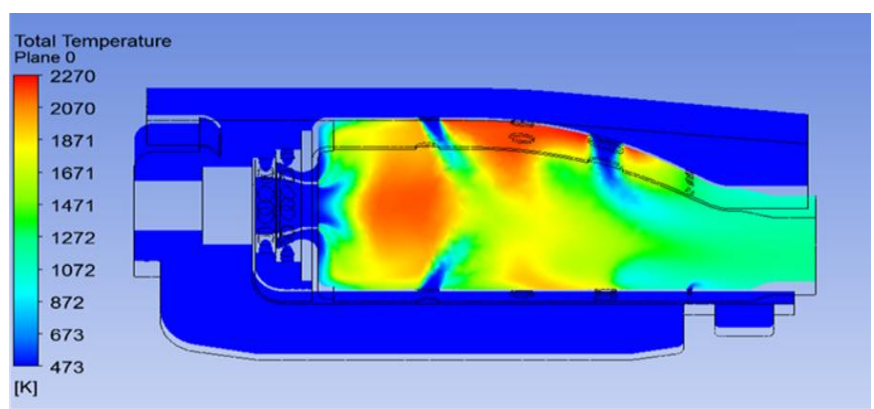

Fig. 5b. Total temperature distribution.

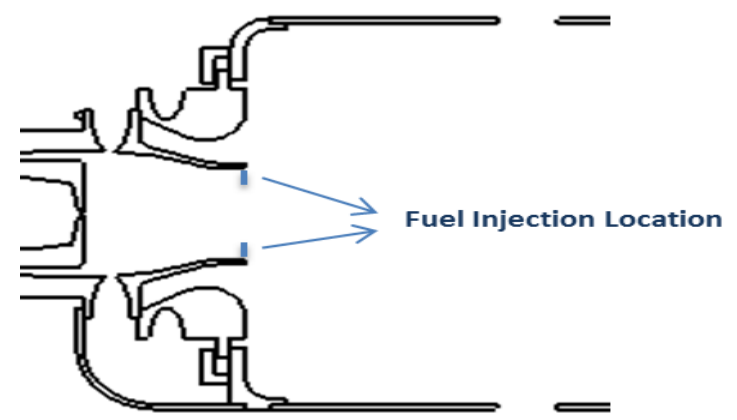

Fig. 6. Fuel Injection Location in CFD model.

One of the most important performance parameters of the combustor design is the outlet temperature profile. OTDF and RTDF parameters are critical for the life of turbine rotor and stator. According to the design criteria, maximum value of the OTDF is 0.3. For RDTF, it can change in respect of the turbine design requirements. Resulted OTDF value $(0.22)$ is achieved the design criteria. However, when radial profile is examined, there is not a good result for the turbine aspect. It can be seen high temperature value at the tip of the combustor exit that is the location of high stress value for the turbine (see Fig. 7).

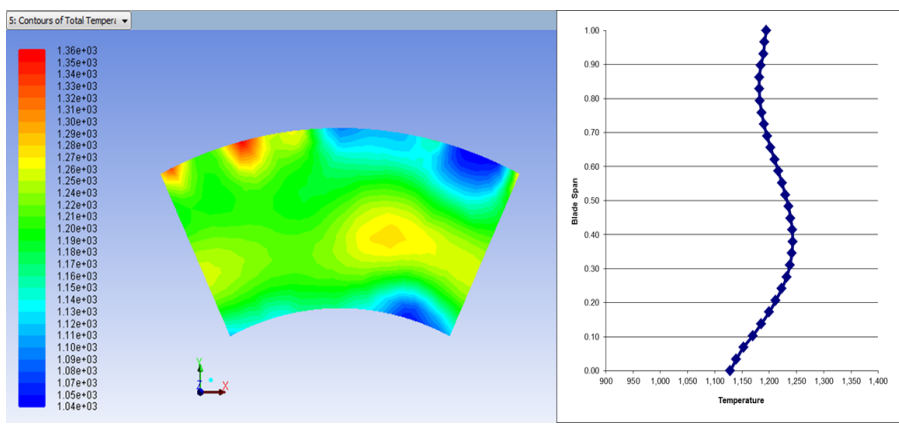

Fig. 7. Outlet temperature distribution of combustor.

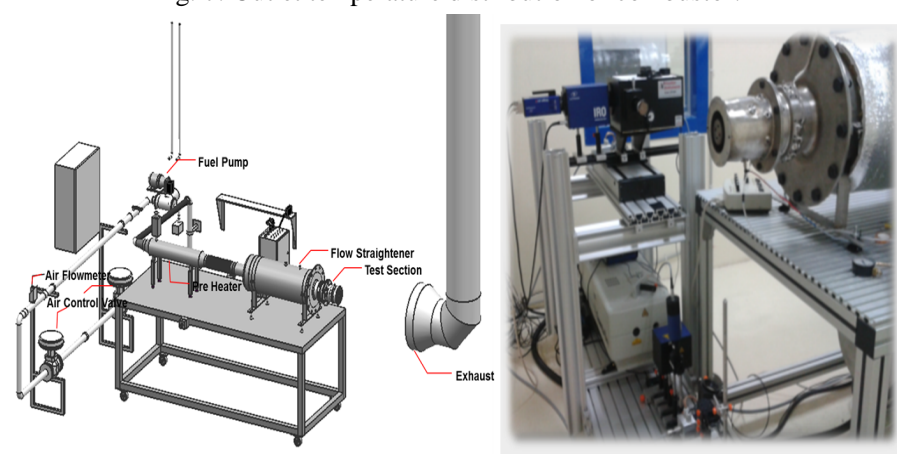

Fig. 8. Overview of the atmospheric combustor test rig.

Aerothermal design of the combustor has been completed and as next step test set-up process started. In combustor validation phase, the first is the atmospheric tests. For this purpose, a test rig has been designed and installed to perform combustor performance characterization tests in a simulated environment. Overview of the combustor test facility is shown in Fig. 8. Test system can dynamically control the air mass flow rate and temperature and fuel temperature.

A special test section has been designed to simulate engine environment. Test section design and flame tube can be seen in Fig. 9. There is two instrumentation locations as inlet and outlet. Total pressure, static pressure and total temperature values are measured at the inlet. At the exit of the combustor, total pressure value is measured. Combustor exit temperature will be scanned by $1 \mathrm{D}$ raman scattering. For the metal temperature, thermocouple and thermal paint application will be performed and results will used to evaluate preliminary design and conjugate heat transfer solutions.
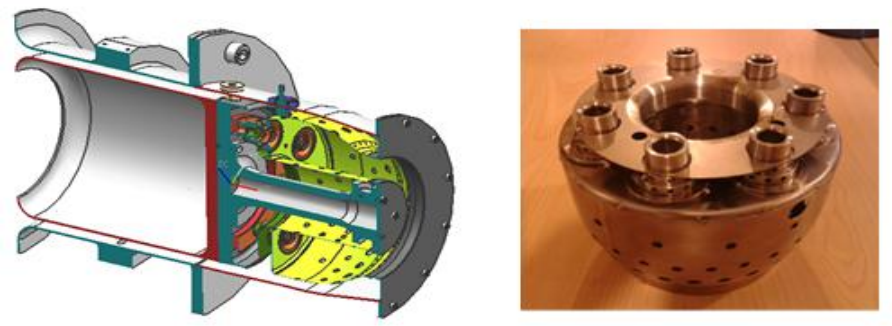

Fig. 9. Test section geometry and flame tube.

\section{CONCLUSIONS}

This study presents an overview of the numeric and experimental studies of a combustor design process. Experimental studies started and first tests of the combustor have been conducted. However data collection studies have not performed yet. Therefore it is not possible to validate the design methodologies and design. As a final step of the design process; it is so critical to get pressure drop, combustion efficiency, exit temperature profile and liner metal temperatures. These values will show the combustor performance character. Moreover, optimization of the radial profile of the combustor must be evaluated for the future work.

\section{NOMENCLATURE}

\author{
$P$ : pressure, $\mathrm{Pa}$ \\ $T$ : temperature, $\mathrm{K}$ \\ $O T D F$ : overall temperature distribution factor \\ $R T D F$ : radial temperature distribution factor \\ $a:$ air \\ $P Z$ : primary zone \\ $S Z$ : secondary zone
}

\section{ACKNOWLEDGEMENTS}

This work was performed as a part of "Combustion chamber development with air-blast fuel-air injector for a small turbojet engine" project and supported financially by the Turkish Republic Ministry of Science, Industry and Technology. Therefore the authors would like to thank ministry for their support. 


\section{REFERENCES}

[1] Y. Panchenko, H. Moustapha, S. Mah, K. Patel, M. J. Dowhan, and D. Hall, "Preliminary multi-disciplinary optimization in turbomachinery design," in Proc. RTO AVT Symposium, Paris, 2002.

[2] J. J. Gouws, "Combining a one-dimensional empirical and network solver with computational fluid dynamics to investigate possible modifications to commercial gas turbine combustor," Faculty of Mechanical/Aeronautical Engineering, University of Pretoria, 2007.

[3] J. Odgers, "Combustion modelling within gas turbine engines, some applications and limitations," AGARD CP 275, 1990

[4] A. H. Lefebvre and D. R. Ballal, Gas Turbine Combustion, CRC Press, 1998.

[5] T. Poinsot, P. Wolf, G. Staffelbach, L. Y. M. Gicquel, and J. D. Muller, "Identification of azimuthal modes in annular combustion chambers, center for turbulence research," Annual Research Briefs, Applied Mathematical Sciences, vol. 5. no. 65, pp. 3221-3232, 2011.
Ahmet Topal is a mechanical engineer in TEI. His specialties are numerical combustion, experimental techniques on gas turbine combustion, thermal paint application, emission measurement.

Onder Turan is an associate professor in the Andolu University, Faculty of Aeronatics and Astronautics. He received his BSc and MSc degrees in the School of Civil Aviation and Graduate School of Sciences at Anadolu University in 1998 and 2000, respectively. He has published many papers at various national and international conferences. He is also a member of many journals and associations. His research areas include aviation, energy and energy economy, gas turbine engines, aircraft propulsion systems and fuels associations.

Sitkı Uslu is an assistant professor in TOBB ETU, Turkey. His specialties are CFD, combustion, heat transfer, fluid mechanics, gas turbines, aerodynamics, aviation, gas turbine engines, aircraft propulsion systems and fuels. 